\title{
Bullefin
}

\section{of the American}
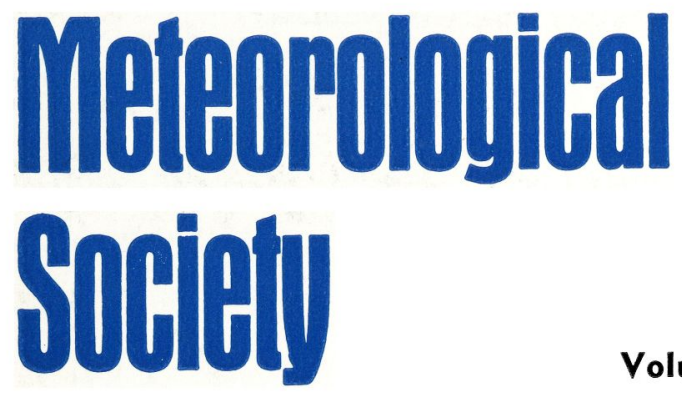

Volume 54 Number 8 August 1973

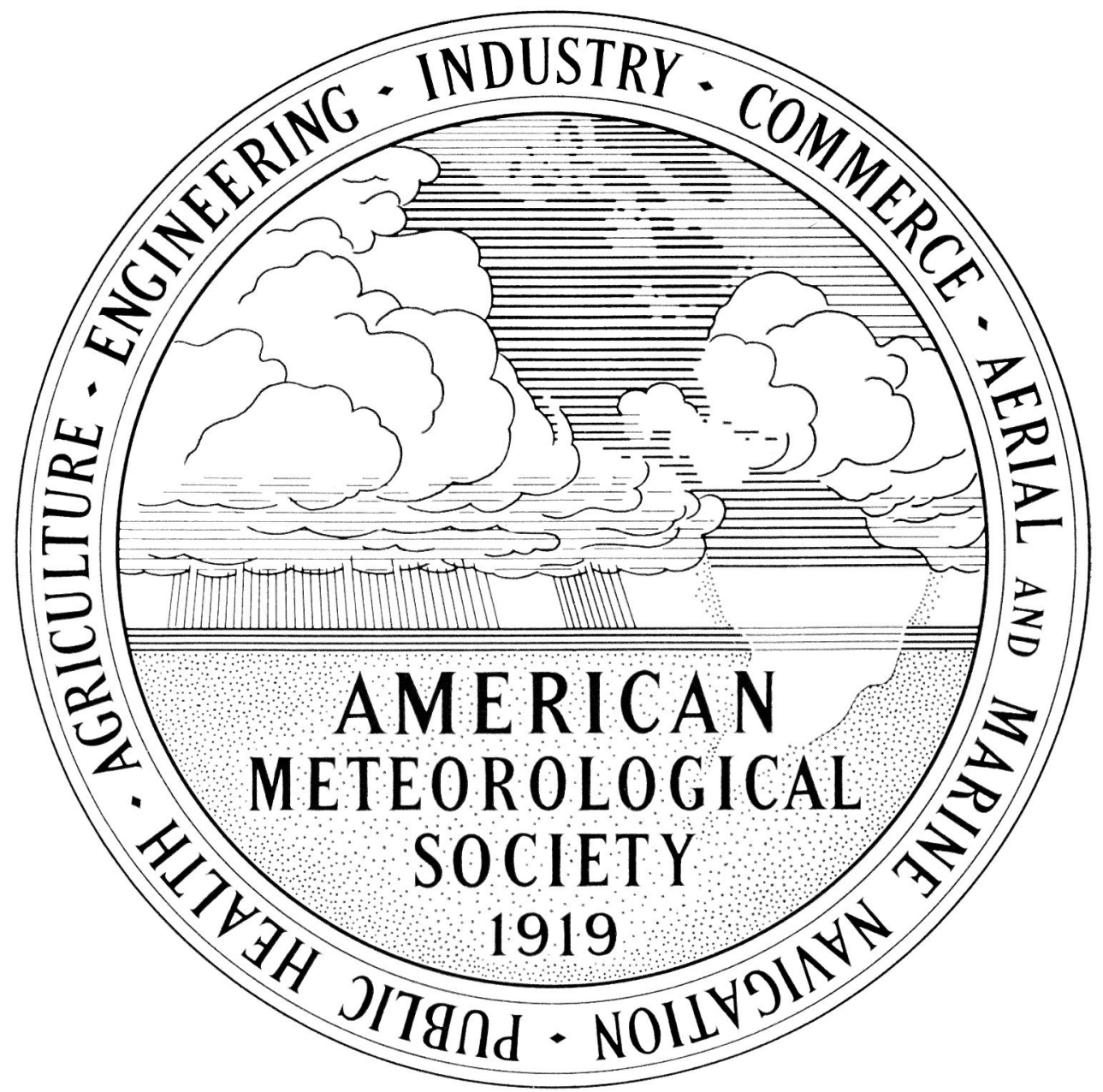




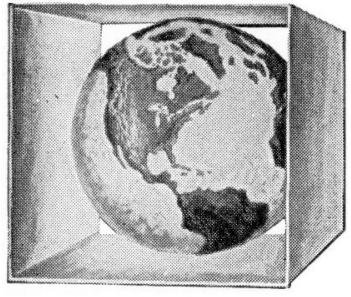

EGгG

\section{Analytical Humidity \& Atmospheric Instrumentation}

Dew Point Hygrometry

The CAMBRIDGE SYSTEMS ${ }^{\circledR}$ Dew Pointer from EG\&G offers a primary measurement of humidity. As an inert metallic mirror is chilled thermoelectrically to the actual atmospheric dew point, the change in reflectance is detected photoelectrically to control the cooler's power supply. Independently, a precision resistance element measures mirror temperature. Dew point temperature is continuously displayed or used for control purposes. This is a fundamental measurement of water vapor partial pressure, and, once known,

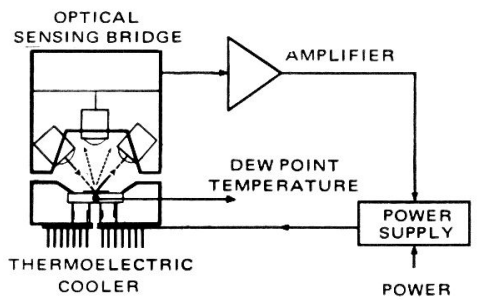

all humidity definitions can be expressed. No calibration gases or chemical resistance grids are used, eliminating aging or contamination problems. Fool-proof standardization is done by automatic mirror heating and nulling out any contamination effects by bridge adjustment. No other instrument offers these standardizing and sensing methods, and because the dew point does not change with ambient temperature, either in-situ sensing or sample tubing from the atmosphere may be used.

\section{Model 110/Weather Station}
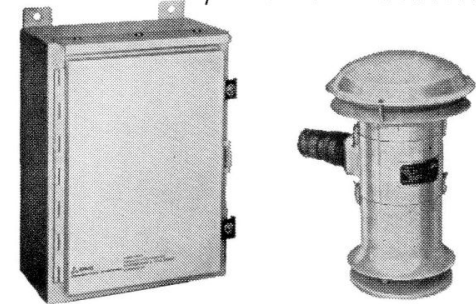

Features

- NBS Platinum Resistance Elements

- Ambient Temperature and

Dew Point

- Automatic Standardizing

- Linear Voltage Outputs (for Recording)

- Fast Response

- $-80^{\circ} \mathrm{F}$ to $+120^{\circ} \mathrm{F}$ Dew Point

Applications

- Synoptic Observations

- Calibration

- Shipboard

- Micrometeorological

Model 137/Aircraft System
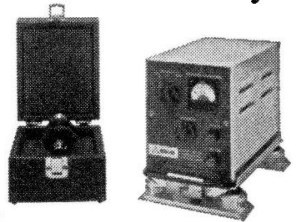

Features

- Miniaturized/Mil/Spec

- NBS Platinum Resistance Element

- Linear Voltage Output (for recording)

- Fast Response

- $-70^{\circ} \mathrm{F}$ to $+160^{\circ} \mathrm{F}$ Dew Point

Applications

- Aircraft Cloud Physics

- Hurricane/Seeding Measurements

- Spacecraft and Underwater Life Support

- Portable and Remote Weather Stations

Model 880/Portable System

Features

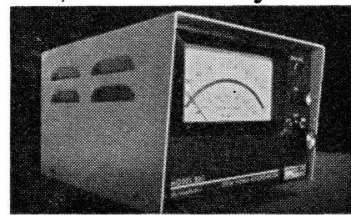

- Precision Thermistor Elements

- Ambient Temperature and Dew Point

- Portable/Self-Contained

- Low Price (\$975.00)

- Wide Range $/-40^{\circ} \mathrm{F}$ to $+120^{\circ} \mathrm{F}$

Dew Point

- Fast Response
Applications

- Calibration Standard

- Air Pollution Monitor

- Agricultural Meteorology

- Life Sciences

Model 992/Calibration

Standard

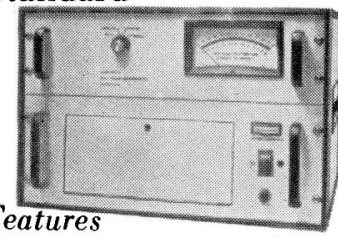

- NBS Platinum Resistance Element

- Automatic Standardizing

- Widest Range $/-100^{\circ} \mathrm{F}$ to $+200^{\circ} \mathrm{F}$ Dew Point

- Multiple Sample Tube Sensing

- Stainless Steel Dew Point Sensor

Applications

- Calibration Standard

- Environmental Chambers and Wind Tunnels

- Remote Sample Line Sensing

Model 207/Forward

Scatter Meter

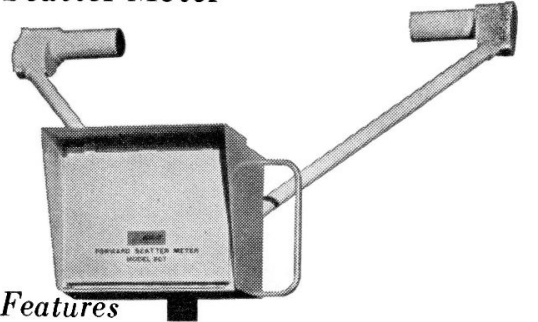

- Measures Visual Range from 200 to 20,000 feet

- Maintains Visual Range accuracy in presence of rain and snow

- Large Sampling Volume

- Single Point Installation

- Simple Field Calibration even under adverse conditions

Applications

- Weather Research Programs

- Air Pollution Studies

- Aircraft Runways
For more information on Cambridge Systems Instrumentation, contact EG\&G, Environmental Equipment Division, 151 Bear Hill Rd., Waltham, Mass. 02154. Tel: 617-890-3710 TWX 710-324-7648

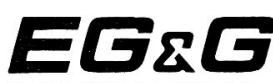

ENVIRONMENTAL EQUIPMENT DIVISION 


\section{We can't prevent this}

\section{..obut we can help
you forecast it}

ALDEN FOFAX weather chart recorders aid prediction of pollution index... It is increasingly important to be able to predict atmospheric conditions which could lead to abnormally high pollution levels in a given area.

Such predictions can be made more easily and with a higher confidence level by the use of information gathered by the National Weather Service and transmitted nationwide on the FOFAX circuit. Daily transmissions include two pollution potential charts in addition to long-range forecast information and photos from orbiting weather satellites.

ALDEN Series 1800 and 1100 Facsimile Recorders are the only fully automatic weather chart recorders specifically designed for operation on the FOFAX circuit. Simple, clean and quiet in operation ... no chemicals, powder or carbon paper. The wide dynamic tone shades of electrosensitive paper provide faster, easier visual interpretation.

For complete data write today, or phone collect and ask for Manager, Weather Systems Sales.
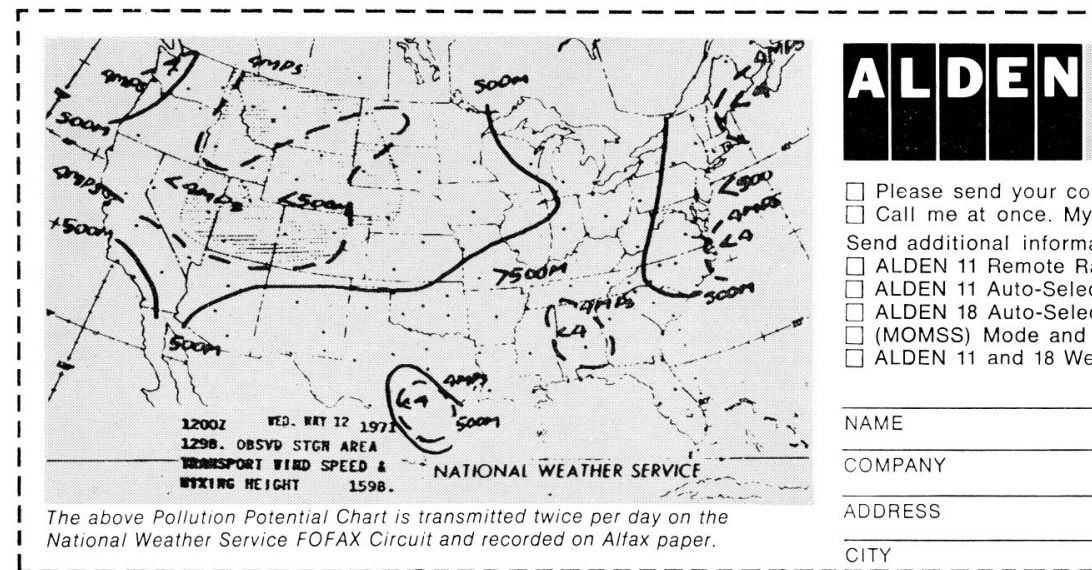

ELECTRONIC \& IMPULSE RECORDING EQUIPMENT CO, INC. WASHINGTON STREET. WESTBORO. MASSACHUSETTS O1581
TELEPHONE (617) 366.8851

$\square$ Please send your complete catalog

$\square$ Call me at once. My telephone number is

Send additional information on

$\square$ ALDEN 11 Remote Radar Recorder
$\square$ ALDEN 11 Auto-Select (APT/FOFAX)

$\square$ ALDEN 18 Auto-Select FOFAX Recorder

$\square$ (MOMSS) Mode and Message Selection System

$\square$ ALDEN 11 and 18 Weather Chart Recorder (Standard networks)

NAME

COMPANY

ADDRESS (20) 


\section{Environmental monitoring. That's us all over.}

Your business requires environmental monitoring? What a coincidence. Our business is supplying it. We're Bendix, and we offer a total environmental monitoring capability. Air monitoring. Water monitoring. Meteorological data acquisition. Power plant site studies, too. All with an eye toward satisfying
EPA regulations and AEC safety guide 23.

We'll custom design equipment to meet your specifications also.

And whatever the job, chances are we'll do it better because we build most of our own equipment. Top-notch, world-famous Bendix instruments.

Now what was that environmental monitoring problem you said you had?

The Bendix Corporation, Environ- mental Science Division, 1400 Taylor Avenue, Baltimore, Maryland 21204. Phone: (301) 825-5200.

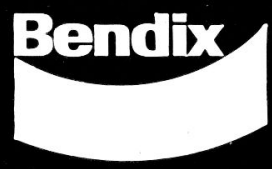

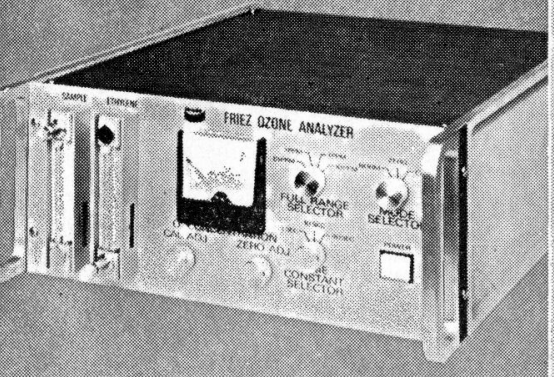

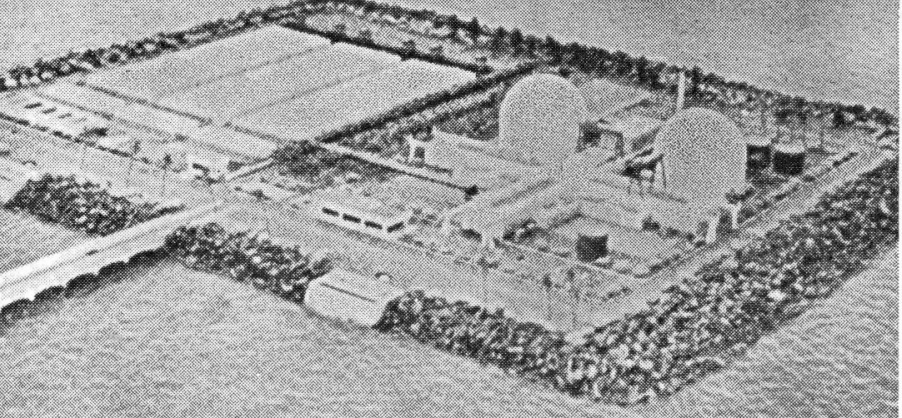




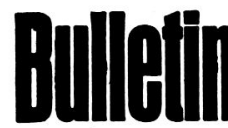

of the American

Meteopological

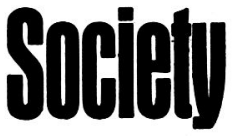

Editor

Kenneth C. Spengler

Technical Editor

Miles F. Harris

News Editor

Sandra A. Waddock

Meetings Editor

Evelyn Mazur

Editorial Assistants

Mari Okie

Lilly G. Albo

volume 54, number 8, August 1973
The Bulletin of the American Meteorological Society is the official organ of the Society, devoted to editorials, survey articles, professional and membership news, announcements, and Society activities. Editing and publishing are under the direction of Kenneth C. Spengler, Executive Director. Members are encouraged to send to the Society information which they wish to be considered for publication.

AMS Officers and Councilors: President, William W. Kellogg; PresidentElect, David S. Johnson; Executive Director, Kenneth C. Spengler; Secretary-Treasurer, David F. Landrigan; Past Presidents, Alfred K. Blackadar and Richard J. Reed; and Councilors: David Atlas, William H. Best, Jr., Robert G. Fleagle, Robert D. Fletcher, Charles L. Hosler, William H. Klein, Max A. Kohler, William J. Kotsch, Richard S. Lindzen, Paul B. Mac Cready, Jr., Patrick D. McTaggart-Cowan, Jerome Namias, Frederick G. Shuman, Silvio G. Simplicio, Warren S. Wooster.

Published monthly at Prince and Lemon Streets, Lancaster, Pa. 17604. Second-class postage paid at Boston, Mass. and at additional mailing offices. Address all business communications, purchase orders and inquiries regarding the Society to the Executive Director, American Meteorological Society, 45 Beacon Street, Boston, Mass. 02108. 617-227-2425.

Cover photograph: The members of the AMS are organized to promote the advancement of meteorology and its applications. The seal of the society, reproduced on the cover, illustrates some of the areas in which meteorology can be applied for the benefit of mankind. The "Organization of the American Meteorological Society," page 781, outlines the manner in which the AMS is organized to achieve these objectives.

Organization Issue

president's page

a policy guide for publications of the AMS

Constitution and By-Laws

organization of the AMS

council of the AMS

presidents, honorary members and fellows of the AMS

members of commissions, boards and committees

directory of local chapters

the Society's awards

calendar of meetings

publications of the AMS

policy statements of the AMS

certification program for consulting meteorologists

seal of approval program for radio and television weathercasting

corporation members of the AMS

the WHO/IAMAP scientific conference on weather modification

\begin{tabular}{ll}
\hline book reviews & 854 \\
\hline news and notes & 856 \\
\hline news from our chapters & 858 \\
\hline announcements & 860 \\
\hline about our members & 862
\end{tabular}

list of new members 